\title{
Endogenous Sunk Cost, Quality Competition and Welfare
}

\author{
George S. Ford ${ }^{1}$, Michael Stern ${ }^{2}$ \\ ${ }^{1}$ The Phoenix Center for Advanced Legal \& Economic Public Policy Studies, \\ Washington, DC, USA \\ ${ }^{2}$ Department of Economics, Auburn University, Auburn, USA \\ E-mail:ford@phoenix-center.org, sternml@auburn.edu \\ Received July 2, 2011; revised August 4, 2011; accepted August 12, 2011
}

\begin{abstract}
Competition in quality with escalating levels of endogenous sunk costs may produce levels of concentration even higher than expected in their absence. We show that consumers may very well benefit from such expenditures despite the effects on concentration and likely attenuation of price competition.
\end{abstract}

Keywords: Sunk Costs, Endogenous Sunk Costs, Quality Competition, Welfare, Market Structure

\section{Introduction}

The number of firms that can supply a given market is not infinite, but bound by the underlying supply-side and demand-side conditions of the market. An excellent presentation of these ideas is provided in John Sutton's seminal treatise, Sunk Costs and Market Structure [1]. Under some simplifying assumptions such as Cournot Competition and unit demand elasticity, the predicted equilibrium number of firms in a market, $N^{*}$, is determined by the formula:

$$
N^{*}=\sqrt{\frac{S}{\sigma}}
$$

where $S$ is market size and $\sigma$ is the sunk cost of entry. Thus, as market size grows, other things remaining constant, the equilibrium number of firms rises. However, as demonstrated in Sutton [1], this is true only if the level of sunk cost is determined exogenously. By "exogenous" we mean that entry costs are determined solely by the technology of production (e.g., plant size, start-up working capital, and so forth), so that the firm has little discretion in choosing the level of $\sigma$.

In some cases quality competition may raise the fixed and sunk costs of a firm's participation in an industry and, in turn, increase equilibrium industry concentration. With only exogenous sunk costs, Expression (1) indicates that the number of firms in equilibrium rises monotonically (always) with market size and market concentration falls. With endogenous sunk costs, once market size reaches some critical value, say $S^{*}$, the incumbent firms begin to intensify competition in quality by escalating investment expenditures in $\mathrm{R} \& \mathrm{D}$, advertising, and activities that will raise the consumers' willingness to pay and attract customers away from firms offering lower quality products. If the increased endogenous sunk cost investments are large enough, then concentration begins to rise as market size grows.

High concentration, particularly in large markets, invariably attracts the attention of policymakers and regulators. A theoretical expectation that increases in market size may result in higher, rather than lower, concentration invites the question: Is the higher concentration resulting from quality competition necessarily good or bad for consumers and economic welfare? From a welfare perspective, the reduced well being of consumers from higher prices due to higher concentration (at least under some assumptions of competitive interaction) is offset, to some extent, by consumers' higher willingness-to-pay for better products and services. Sutton [1], however, eschews welfare analysis, thereby providing no answer. In this Letter, we fill in that gap.

\section{Analysis}

Since our interest in this topic is drawn from Sutton's book, we look there to begin our analysis. In Section 3.2, Sutton utilizes a Cobb-Douglas specification for modeling consumer utility. This choice implies that the representative consumer chooses a good that maximizes the ratio of quality $(u)$ to price $(p)$. The quality-to-price ratio $(u / p)$ is a simple index of consumer welfare. This 
metric is superior to alternatives such as aggregate utility since it does not automatically scale when market size is increased due to either an increase in the number of consumers or consumer income.

Let market concentration be defined as $x=1 / N$, where $N$ is the number of firms. Inserting this measure of concentration into Equation (3) from Sutton [1] and rearranging yields:

$$
x^{3}-\left(2+\frac{\gamma}{2}\right) x^{2}+x=\frac{\gamma \sigma-a}{2 S}
$$

where $a$ is the cost per advertising message, and $\gamma$ measures the returns to advertising or other expenditures which increase consumers' willingness-to-pay. Given a set of parameter values $(a, \sigma, \gamma)$ and market size $(S)$, this cubic equation yields the equilibrium level of market concentration when firms are in the interior of their profit maximization problem with respect to quality $(u>1)$. If the market size is relatively small, the firms will be on the quality boundary $(u=1)$ and the equilibrium concentration is given by:

$$
x^{2}=\frac{\sigma}{S}
$$

The critical point $\left(S^{*}, x^{*}\right)$ where the equilibrium concentration switches from (3) to (2) is characterized by the solution to the system:

$$
x^{2}-\left(2+\frac{a}{2 \sigma}\right) x+1=0
$$

and

$$
S=\sigma / x^{2}
$$

The above system merely involves a quadratic equation, and is therefore easy to solve. With the critical point $\left(S^{*}, x^{*}\right)$ calculated, Equation (3) can be used to calculate the equilibrium concentration for any market size, $S \leq S^{*}$. Finally, Equation (2) can be used to calculate the equilibrium concentration for any market size $S>S^{*}$.

After calculating the equilibrium concentration level for a given market size, one can calculate the equilibrium price and quantity in the market. The equilibrium price is given at Sutton [1, p. 50], and can be written in terms of concentration:

$$
p=c /(1-x),
$$

where $c$ is marginal cost. Whenever $S \leq S^{*}$, the equilibrium quality is simply equal to one. However, when $S>$ $S^{*}$, the equilibrium quality level can be calculated using Equation (1) on Sutton [1, p. 54]. Writing the equation in terms of concentration and substituting in for the fixed cost function $(F)$ yields the following characterization of equilibrium quality:

$$
u=\left(\frac{2}{a} S x(1-x)^{2}\right)^{1 / \gamma} \quad \text { if } \quad S>S^{*}
$$

$$
u=1 \quad \text { if } \quad S \leq S^{*}
$$

Finally, the ratio of the equilibrium quality $(u)$ to market price $(p)$ can now be formed in order to characterize consumer welfare.

Generally speaking, in a model with fixed costs, one would expect efficiency gains from increased market size. Given the endogenous entry and zero profit condition in Sutton's model, firm welfare cannot rise and hence we would expect the welfare gains to be captured by consumers. Before firms invest in quality $(u)$, an increase in market size simply results in more firms, a lower price level, and hence higher consumer welfare.

After $S^{*}$, firms begin investing in quality, the number of firms slowly falls, and the market price rises (by the Cournot assumption), but the rate of increase in quality will generally far outweigh the higher market price. Thus, the consumer welfare ratio $(u / p)$ will continue to rise as market share increases.

As an example, we plot in Figure 1 the consumer welfare ratio $(u / p)$ as a function of market size $(S)$ for the following parameter values: $a=300, \sigma=101, \gamma=2$, and $c=1$. The simulation produces the expected size-concentration relationship with $S^{*}=1000$. Consumer welfare rises as market size increases, even after the concentration "switch point" $\left(S^{*}\right)$. Thus, our analysis demonstrates that when higher concentration results from competition in quality with escalating endogenous sunk costs where those costs are incurred to raise willingness-to-pay, consumer welfare rises despite the reduction in the equilibrium number of firms.

\section{Conclusions}

Competition in quality with escalating levels of endogenous sunk costs may produce levels of concentration even higher than expected in their absence. But we show, based on the analysis in Sutton [1], that consumers may very well benefit from such expenditures despite the effects on concentration and likely attenuation of price competition. This result may have significant public pol-

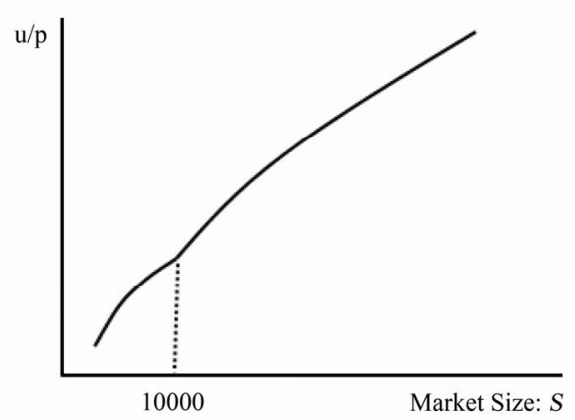

Figure 1. Welfare and market size. 
icy relevance for competition in communications markets, where sunk costs are prevalent and quality competetion is a primary instrument of rivalry.

\section{Acknowledgements}

The authors are grateful for helpful comments and sug- gestions on this work provided by Randy Beard, Jerry Duvall, and Lawrence Spiwak.

\section{Reference}

[1] J. Sutton, "Sunk Cost and Market Structure," MIT Press, Cambridge, 1991. 